\title{
Hybrid nanobiocomposites based on poly(3-hydroxybutyrate) - characterization, thermal and mechanical properties
}

\author{
IWONA ZARZYKA ${ }^{1 *}$, ANNA CZERNIECKA-KUBICKA ${ }^{2,3}$, AGNIESZKA SZYSZKOWSKA ${ }^{1}$, \\ MAREK PYDA ${ }^{1}$, WIESŁAW FRĄCZ ${ }^{3}$, ŁUKASZ BYCZYŃSKI ${ }^{4}$, VLADIMIR SEDLARIK ${ }^{5}$ \\ ${ }^{1}$ Department of Organic Chemistry, Faculty of Chemistry, Rzeszow University of Technology, Rzeszów, Poland. \\ ${ }^{2}$ Department of Experimental and Clinical Pharmacology, Faculty of Medicine, The University of Rzeszow, Rzeszów, Poland. \\ ${ }^{3}$ Department of Integrated Design Systems and Tribology, Faculty of Mechanics and Technology, \\ Rzeszow University of Technology, Stalowa Wola, Poland. \\ ${ }^{4}$ Department of Polymers and Biopolymers, Faculty of Chemistry, Rzeszow University of Technology, Rzeszów, Poland. \\ ${ }^{5}$ Centre of Polymer Systems, Tomas Bata University in Zlin, Czech Republic.
}

\begin{abstract}
Poly(3-hydroxybutyrate) is a biopolymer used to production of implants in the human body. On the other hand, the physical and mechanical properties of poly(3-hydroxybutyrate) are compared to the properties of isotactic polypropylene what makes poly(3-hydroxybutyrate) possible substitute for polypropylene. Unfortunately, the melting point of poly(3-hydroxybutyrate) is almost equal to its degradation temperature what gives very narrow window of its processing conditions. Therefore, numerous attempts are being made to improve the poly(3-hydroxybutyrate) properties.

In the present work, hybrid nanobiocomposites based on poly(3-hydroxybutyrate) as a matrix with the use of organic nanoclay - Cloisite 30B and linear polyurethane as a second filler have been manufactured. The linear polyurethane was based on diphenylmethane 4,4'-diisocyanate and diol with imidazoquinazoline rings. The obtained nanobiocomposites were characterized by X-ray diffraction, scanning and transmission electron microscopies, thermogravimetry, differential scanning calorimetry and their selected mechanical properties were tested. The resulting hybrid nanobiocomposites have intercalated/exfoliated structure. The nanobiocomposites are characterized by a higher thermal stability and a wider range of processing temperatures compared to the unfilled matrix. The plasticizing influence of nanofillers was also observed. In addition, the mechanical properties of the discussed nanobiocomposites were examined and compared to those of the unfilled poly(3-hydroxybutyrate). The new-obtained nanobiocomposites based on poly(3-hydroxybutyrate) containing $1 \%$ Cloisite $30 \mathrm{~B}$ and $5 \mathrm{wt}$. \% of the linear of polyurethane characterized the highest improvement of processing conditions. They have the biggest difference between the temperature of degradation and the onset melting temperature, about $100^{\circ} \mathrm{C}$.
\end{abstract}

Key words: hybrid nanobiocomposites, poly(3-hydroxybutyrate), nanoclay, linear polyurethanes, thermal stability, mechanical properties

\section{Introduction}

Waste from the degradation of plastics is a serious problem because of an increasing use of such materials in various industry branches. In order to avoid the formation of harmful waste, biodegradable compounds are used for the production of plastics. These types of com- pounds include polyhydroxyalkanoates, which are derivatives of $\beta$-hydroxyacids. Biocompatibility and lack<smiles>CCCCC(=O)CC(C)OC(C)(C)C</smiles>

Fig. 1. Structure of $\mathrm{P} 3 \mathrm{HB}$

\footnotetext{
* Corresponding author: Iwona Zarzyka, Department of Organic Chemistry, Faculty of Chemistry, Rzeszow University of Technology, ul. Powstańców Warszawy 6, 35-959, Rzeszów, Poland. Phone: +480178651762, fax:+480178543655, e-mail: izarzyka@prz.edu.pl

Received: October 11th, 2019

Accepted for publication: January 24th, 2020
} 
of toxicity allow for their use in accordance with the principles of "green chemistry". Poly(3-hydroxybutyrate) - P3HB, which structure is shown in Fig. 1, is one of the most important polyhydroxyalkanoates.

P3HB is produced naturally by various types of bacteria such as, e.g., Rhodobacter which accumulate it as a reserve material. When the $\mathrm{P} 3 \mathrm{HB}$ content reaches $80 \%$ of the dry mass of the bacteria, raw $\mathrm{P} 3 \mathrm{HB}$ is isolated by extraction and purified. On the other hand, $\mathrm{P} 3 \mathrm{HB}$ is nourishment for bacteria, thus it is easily biodegradable [14].

P3HB plays biologically important functions in human body due to its role in the construction of channels located in cell membranes that enable the transport of calcium ions. P3HB has low toxicity because it decomposes in vivo to 3-hydroxybutyric acid which is a natural metabolite in human blood [11]. P3HB is biocompatible, therefore it can be used in medicine as implants in human body including pericardial substitutes after cardiac surgery, materials for "patching" intestinal damage, channels for repairing longer breaks in peripheral nerves, scaffolding for neurons and regeneration after spinal cord injury or stitching materials [5], [12], [13].

$\mathrm{P} 3 \mathrm{HB}$ is insoluble in water and relatively resistant to hydrolysis, which distinguishes it from other biodegradable polymers that are either water soluble or moisture sensitive. P3HB is insensitive to ultraviolet radiation but is sensitive to acids and bases [13]. $\mathrm{P} 3 \mathrm{HB}$ is a highly crystalline polyester (over $50 \%$ ) with a high melting temperature, $T_{m}=173-180{ }^{\circ} \mathrm{C}$, compared to other biodegradable polyesters. The glass transition temperature $\left(T_{g}\right)$ of $\mathrm{P} 3 \mathrm{HB}$ is around $5{ }^{\circ} \mathrm{C}$. The physical and mechanical properties of $\mathrm{P} 3 \mathrm{HB}$ are compared to those of isotactic polypropylene. It makes P3HB a very attractive material because it could be a substitute for polypropylene [6], [9], [10], [12], [19], [23].

P3HB can be extruded, cast and molded using a conventional processing equipment. $\mathrm{P} 3 \mathrm{HB}$ products are ductile after forming. Unfortunately, storing the $\mathrm{P} 3 \mathrm{HB}$ products at room temperature causes deterioration of the product properties and the material becomes very brittle. These disadvantages of $\mathrm{P} 3 \mathrm{HB}$, i.e., rigidity, brittleness and low thermal stability, which is almost equal to its melting point, limit the commercial use of P3HB on a large scale. The thermal instability of this polymer during melting makes replacing commercial non-biodegradable polymers by $\mathrm{P} 3 \mathrm{HB}-$ based ones difficult because of the narrow window for processing conditions [7], [18].
One way to modify the properties of $\mathrm{P} 3 \mathrm{HB}$ is the production of nanocomposites with its contribution as a matrix. Researches confirm that the addition of several percent (usually $1-5 \%$ ) of nano-filler leads to obtaining nanocomposites with better properties compared to the neat $\mathrm{P} 3 \mathrm{HB}$ [7], [21]. The P3HB nanocomposites with $1 \mathrm{wt}$. \% of Cloisite $30 \mathrm{~B}$ showed the best properties, i.e., a decrease in the glass transition, melting and crystallization temperatures. The decrease in the melting point of the composites facilitate processing and prevents the degradation of the material. Furthermore, the $\mathrm{P} 3 \mathrm{HB}$ showed improved impact strength, flexural modulus and slightly flexural strength [7].

Additionally, nanobiocomposites are very interesting materials because they show improved properties while maintaining a good degree of biodegradability of the material and its non-toxicity. These types of materials are mainly intended for biomedical applications and other short-term applications, e.g., for the production of packaging, in agriculture or in hygiene devices [21], [15].

The production of composites involving two or more types of filler gives even more opportunities to modify the properties of the polymers. A properly selected combination of composite components allows for obtaining materials with better properties than in the case of using one type of filler.

Bakar et al. confirmed the improvement of the properties of hybrid nanocomposites based on epoxy resin in terms of impact strength, critical stress intensity factor and bending strength compared to unmodified epoxy resin and modified with polyurethanes or nanoclay only. Similar relationships were observed in the case of nanocomposites obtained on the basis of epoxy resin, nanoclay Cloisite $30 \mathrm{~B}$ and polyurethanes derived from toluene 2,4-diisocyanate (TDI) or 4,4'-diphenylmethane diisocyanate (MDI) and polyethylene glycol or polyoxypropylene diol [1]-[3], [16], [17].

Thus, the production of nanocomposites or hybrid nanocomposites allows for the significant improvement in the properties of the unfilled polymer. Simultaneous use of nanofiller and polyurethane as the second filler results in better improvement of nanocomposite properties compared to the properties of an unfilled matrix or composite containing only one filler. Given the above facts, in our research we also undertaken the problem of modifying the properties of materials based on P3HB. For this purpose, linear polyurethanes with thermally stable imidazoquinazoline rings (PU-MDI) together with organic nanoclay Cloisite $30 \mathrm{~B}$ were used to obtain hybrid 
nanocomposites with $\mathrm{P} 3 \mathrm{HB}$ as a continuous phase. It was expected to improve their properties compared to the unfilled $\mathrm{P} 3 \mathrm{HB}$, especially processing and thermal properties, and perhaps also mechanical properties.

\section{Materials and methods}

\subsection{Materials}

P3HB was provided by Biomer (Krailling, Germany). Its average molecular mass $M_{w}=443.900 \mathrm{~g} / \mathrm{mol}$ and dispersity $D_{M}=M_{w} \cdot M_{n}^{-1}=5.72$, as determined by size exclusion chromatography in chloroform. Its melt flow index was $0.11 \mathrm{~g} \cdot(10 \mathrm{~min})^{-1}\left(180{ }^{\circ} \mathrm{C}\right.$ at $\left.2.16 \mathrm{~kg}\right)$. Cloisite 30B, i.e., montmorillonite modified with methylbis(2-hydroxyethyl)tallowalkylammonium cations was supplied by Southern Clay Products Inc. (Gonzales, US).

Polyurethane with imidazoquinazoline ring based on diphenylmethane 4,4'-diisocyanate (PU-MDI) was obtained according to procedure [24]. Reaction was carried out in anhydrous N,N-dimethylformamide (DMF) at temperature $90{ }^{\circ} \mathrm{C}$ under nitrogen atmosphere. MDI dissolved in DMF was added dropwise to solution of 2,6-bis(2-hydroxyethyl)-1-phenylimidazo[1,5-c]quinazoline-3,5-dione (BHPIQ) with dibutyltin dilaurate (DBTL). The reaction progress was monitored by checking of NCO groups contents. The product was purified by precipitated from cold acetone.

\subsection{Nanobiocomposites preparation}

Nanobiocomposites were obtained by mixing the melt P3HB with 1 wt. \% of Cloisite $30 \mathrm{~B}$ clay and 1 or 5 wt. \% of PU-MDI (marked as P3HB-1.1 and P3HB-1.5, respectively) in a co-rotating twin screw extruder. Previously, $\mathrm{P} 3 \mathrm{HB}$ was dried at $40{ }^{\circ} \mathrm{C}$ under reduced pressure for $30 \mathrm{~min}$. In turn, nanoclay was dispersed in water using ultrasonic sonicator at room temperature for $2 \mathrm{hrs}$. Then, the nanoclay was filtered and dried at $40{ }^{\circ} \mathrm{C}$ under reduced pressure. In order to obtain reference materials, the unfilled $\mathrm{P} 3 \mathrm{HB}$ and $\mathrm{P} 3 \mathrm{HB}$ with $1 \mathrm{wt} \%$ of nanoclay (marked as P3HB-1) were also extruded. The twin screw extruder was equipped with the four temperature controlled zones, which were programmed in the range from 150 to $185^{\circ} \mathrm{C}$. The screw diameter was $12.5 \mathrm{~mm}$ and the $\mathrm{L} \cdot \mathrm{D}^{-1}$ ratio was 24 . The screw speed during process was $40 \mathrm{rpm}$. Extrusion conditions were determined experimentally.

\section{Analytical methods}

\subsection{Scanning electron microscopy}

In order to characterize the phase morphology of all nanobiocomposites, i.e., P3HB-1, P3HB-1.1 and $\mathrm{P} 3 \mathrm{HB}-1.5$ and the unfilled $\mathrm{P} 3 \mathrm{HB}$ the scanning electron microscopy (SEM) was used. Before the measurements, tested surfaces were coated with a thin layer of gold in a sputtering process. A HITACHI S-3400 N scanning electron microscope was used at various image magnifications and an accelerated voltage of $10 \mathrm{kV}$.

\subsection{WAXS analysis}

Wide Angle X-ray Scattering (WAXS, X'Pert Pro PANalytical) were applied to gain information about the structure phases of the obtained biocomposites. A Cu-K- $\alpha(1.5406 \AA)$ ray was used for the analysis. The scan rate was set to $1^{\circ} \cdot \mathrm{min}^{-1}$, the imposed voltage and current were $30 \mathrm{kV}$ and $10 \mathrm{~mA}$, respectively, and the diffraction angle $(2 \theta)$ was varied from 10 to $70^{\circ}$ at a rate of $0.02^{\circ} \cdot \mathrm{min}^{-1}$.

\subsection{SAXS analysis}

In order to check the nanostructure of biocomposites Small Angle X-ray Scattering (SAXS) measurements were performed. Tests were made at room temperature by using X-ray diffractometer Bruker SAXS Nanostar-U. Comparative spectra for compression molded samples were investigated in the transmission mode (coupled $\mathrm{h} \cdot 2 \mathrm{~h}^{-1}$ ) to check the effect of the nanoparticles orientation. A small angle goniometer was coupled to a sealed-tube source of filtered $\mathrm{Cu}-\mathrm{K}-\alpha$ radiation $(1.54 \AA)$ operating at $50 \mathrm{kV}$ and $0.6 \mathrm{~mA}$. The slit system enabled collection of diffracted beam with the divergence angle of less than 0.05 . Measurements were carried out in the range from 0 to $10^{\circ}$ of $2 \theta$.

\subsection{Transmission electron microscopy}

Transmission electron microscopy (TEM) was used to study the nanostructure features of selected nanobiocomposites. TEM analysis of obtained composites was performed on a JEM-2100, Jeol, Ltd., Japan 
(LaB6 source) equipped with a FEI Eagle 4k CCD camera, operating with an acceleration voltage of $80 \mathrm{kV}$. Before the analysis, cryo-ultramicrotomed sections of the samples were realized and placed on 300 mesh copper grids.

\subsection{TG analysis}

Thermogravimetric analyses of $\mathrm{P} 3 \mathrm{HB}$ and their nanocomposites were performed using a Mettler Toledo TGA/DSC1 apparatus. The experiments have been carried out in the temperature range $25-700{ }^{\circ} \mathrm{C}$ at a heating rate of $10{ }^{\circ} \mathrm{C} \cdot \mathrm{min}^{-1}$ in the nitrogen atmosphere. The following measurement conditions were used: sample weight $\sim 10 \mathrm{mg}$, gas flow $50 \mathrm{ml} \cdot \mathrm{min}^{-1}, 150 \mu \mathrm{l}$ open alumina pan.

\subsection{DSC and TMDSC analysis}

Dependences of heat flow rate on temperature were obtained using the differential scanning calorimeter (DSC), Q2500 from TA Instruments. All analyses were carried out in a nitrogen atmosphere with a constant flow rate of around $50 \mathrm{ml} \cdot \mathrm{min}^{-1}$. In order to obtain very accurate measurements, the temperature calibration and the heat flow rate calibration were performed in reference to the melting parameters of indium, i.e., the onset temperature equals $429.6 \mathrm{~K}$ and the heat of fusion, $\Delta H_{f}=28.45 \mathrm{~J} / \mathrm{g}(3.28 \mathrm{~kJ} / \mathrm{mol})$. The calibration of heat capacity was also carried out in order to improve quality of obtained results. Three measurements, i.e., a calibration with sapphire, a blank (reference) and the actual samples composites were performed for each one of measured sample. The experiments were performed in the temperature range of -90 to $195{ }^{\circ} \mathrm{C}$. The accuracy of heat capacity measurements is around $3 \%$ [8], [20], [22], [25]. The measurements were carried out using a different cooling rate in range of $1{ }^{\circ} \mathrm{C} \cdot \mathrm{min}^{-1}$ to $40{ }^{\circ} \mathrm{C} \cdot \mathrm{min}^{-1}$ and the same heating rate of $10^{\circ} \mathrm{C} \cdot \mathrm{min}^{-1}$.

\subsection{Strength tests}

Samples for strength tests were produced in the injection molding technology on a DrBoy 50 injection molding machine equipped with a Priamus production supervision and monitoring system. These samples were made in accordance with the standard PN EN ISO 527 (1998). All samples were formed with the same adjustable injection parameters, which enabled the assessment of changes in plastic condition parameters in the injection mold.

The tests were carried out at room temperature on a Zwick Roell Z030 testing machine equipped with an automatic multi-strain gauge, with a machine grip speed of $50 \mathrm{~mm} \cdot \mathrm{min}^{-1}$. Young's modulus was determined at a speed of $1 \mathrm{~mm} \cdot \mathrm{min}^{-1}$. The tests were performed for at least seven samples in the series. From each produced series of samples, only those that guaranteed adequate quality were selected for testing. The tensile strength of the samples was tested using the INSTRON impact hammer according to the standard ISO 8256-A-4J. The notch was cut on both sides according to method A of the aforementioned standard.

The hardness of the obtained nanobiocomposite samples was determined by the Brinell method according to standard PN-EN ISO 6506-1:2006. Samples were made in accordance with the standard PNEN ISO 527-1.

\section{Results}

In the present work, the hybrid nanobiocomposites with $\mathrm{P} 3 \mathrm{HB}$ as matrix, $1 \mathrm{wt}$ \% of Cloisite $30 \mathrm{~B}$ as nanofiller and linear polyurethane with imidazoquinazoline rings based on MDI (PU-MDI) as second filler were produced. PU-MDI was used in an amount of 1 and 5 wt. \% (P3HB-1.1 and P3HB-1.5, respectively). At the same time, in order to reliably compare the impact of linear polyurethane on the properties the new nanobiocomposites, a composite containing $1 \mathrm{wt} \%$ of organic nanoclay (P3HB-1) was produced. The unfilled P3HB was also extruded under the same conditions.

The selection of the composite components and their amount was done based on our previous research [7] and the research conducted by Bakar and coworkers [1]-[3], [16], [17]. Composites with the best thermal and mechanical properties were obtained with the use of $1 \%$ of Cloisite 30B [7]. In turn, comparison of properties composites based on epoxy resins as matrix and nanoclay or linear polyurethanes as filler or hybrid composites containing both fillers shown that the best properties have hybrid composites. It should be emphasized that Bakar obtained the best improvement in the properties of the hybrid composites based on epoxy resin involving Cloisite $30 \mathrm{~B}$ and polyurethanes based on MDI [2].

\section{Nanocomposites structure}

$\mathrm{X}$-ray diffraction (XRD) technique was used to characterize the structure of the prepared biocompo- 
sites. The measurements were made in the $2 \theta$ angle range from 1.5 to $70^{\circ}$, and the results were shown in Fig. 2a. The magnification of the diagnostic area from 1.5 to $6.0^{\circ}$ was shown in Fig. $2 b$.

All obtained biocomposites do not have diffraction peaks in the range from 1.5 to $6^{\circ}$ (Fig. 2a). An enlargement of this area (Fig. 2b) indicates the peak intensity within the noise limits. It enabled us to suppose that the obtained nanobiocomposites have exfoliated structure.

It should be noted that some peaks observed in the range of $0-70^{\circ}$ sharp and narrow (e.g., at about $\left.13,18,23,24^{\circ}\right)$ and some of them are wide and mild $\left(19.5-22^{\circ}\right.$ and above $\left.29.5^{\circ}\right)$. It indicates crystalline and amorphous character of the obtained nonobiocomposites.

a.

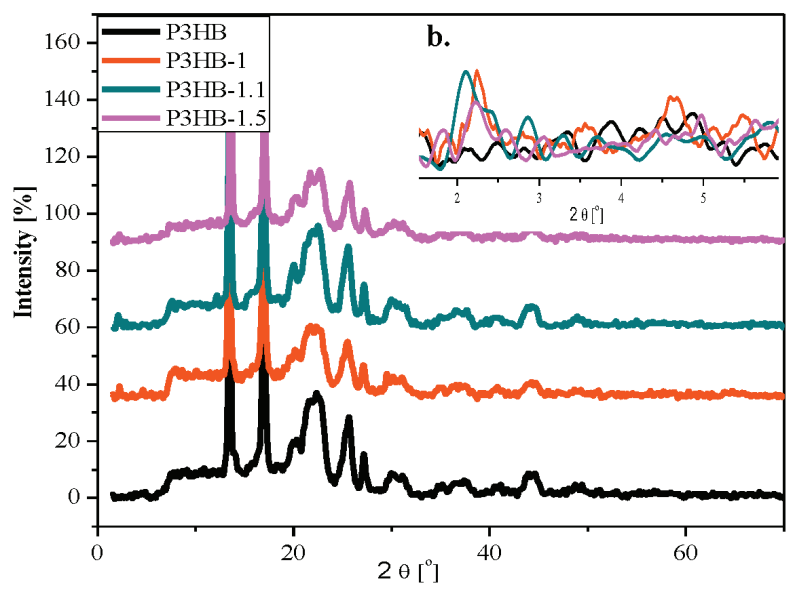

Fig. 2. WAXS diffractograms of biocomposites containing 1 wt. $\%$ of Cloisite $30 \mathrm{~B}$ and 1 or 5 wt. \% of PU-MDI (designated as P3HB-1.1, P3HB-1.5, respectively).

The figure contains reference diffractograms of the unfilled $\mathrm{P} 3 \mathrm{HB}$ and composite $\mathrm{P} 3 \mathrm{HB}$ containing 1 wt. $\%$ of Cloisite $30 \mathrm{~B}$ (P3HB-1). Part b (insert) shows an enlargement of the angle area within $2 \theta=0-6^{\circ}$

In order to confirm the proper interpretation of WAXS diffractograms, the SAXS measurements of the resulted biocomposites were made. The results are shown in Fig. 3. SAXS diffractogram of the unfilled P3HB shows only background scattering with low intensity in the whole range of $2 \theta=1-10^{\circ}$. The diffractogram of the nanofiller Cloisite 30B has a peak with a maximum diffraction of about $2 \theta=4.92^{\circ}$. The montmorillonite structure is determined using the Bragg equation, which allows you to calculate the values of the distance $d$ between nanoclay plates. The diffraction peak with maximum $4.92^{\circ}$ means $d_{001}=1.8 \mathrm{~nm}$.

There are no distraction peaks in the range of $2 \theta=2-10^{\circ}$ on diffractograms of all biocomposites. The diffraction peaks are visible on the diffractograms of all tested composites in the $0.8-2.0^{\circ}$ range. The peaks with a diffraction maximum at a lower value $2 \theta<2^{\circ}$ in the case of all composites means that $\mathrm{P} 3 \mathrm{HB}$ chains penetrated between the layers of nanoclay stacks and the interlayer distance increased. A decreasing of angle diffraction is indicative for the intercalation of the layered silicate with the matrix constituents. The interlayer distance $\left(d_{001}\right)$ between nanoclay plates was calculated based on the Bragg's equation $(\lambda=2 d \cdot \sin \theta)$. The diffraction maximum is located at $2 \theta=1.55,1.60$ and $1.65^{\circ}$, i.e., the interlayer spacing values $\left(d_{001}\right)$ are $5.7,5.5$ and $5.4 \mathrm{~nm}$ for nanobiocomposites P3HB-1.5, P3HB-1.1 and P3HB-1, respectively. The increase of the interlayer distance becomes slightly higher with the filler content decrease, the some shift of the maximum peak is observed. The diffractogram of nanobiocomposite $\mathrm{P} 3 \mathrm{HB}-1.5$ shows the small, second diffraction seen at $2 \theta=2.18^{\circ}$ which corresponds with the second registry $\left(d_{002}\right)$. The peak confirms the intercalated structure the nanocomposites. Nevertheless, it should be emphasized that the intensity of the mentioned peaks is not high. The diffractograms of all nanobiocomposites indicate their good tactoids dispersion.

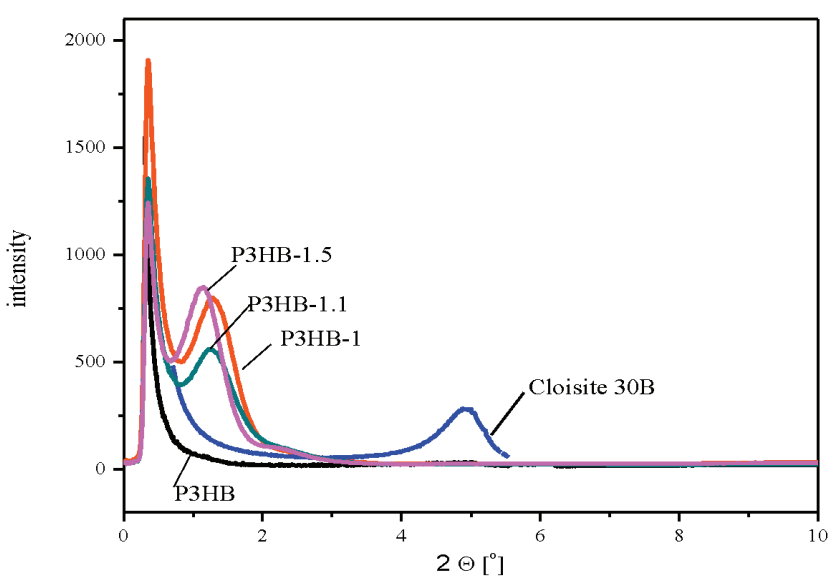

Fig. 3. SAXS diffractograms of nanobiocomposites P3HB-1.1, P3HB-1.5,P3HB-1 and the unfilled P3HB and Cloisite 30B

P3HB-based nanobiocomposites were further analyzed by means of TEM. Selected TEM photomicrographs of the nanobiocomposites are shown in Fig. 4. Figure $4 \mathrm{~b}$ presents the structure of the nanocomposite with 1 wt. \% of Cloisite 30B. Dark lines represent the cross sections of the clay layers and the gray area corresponds to the polymer matrix (Fig. 4a).

In Figure $4 \mathrm{~b}$ the structure of the nanocomposite with 1 wt. \% of Cloisite 30B is presented. Dark lines represent the cross-sections of the clay layers and the gray area corresponds to the polymer matrix (Fig. 4a). 

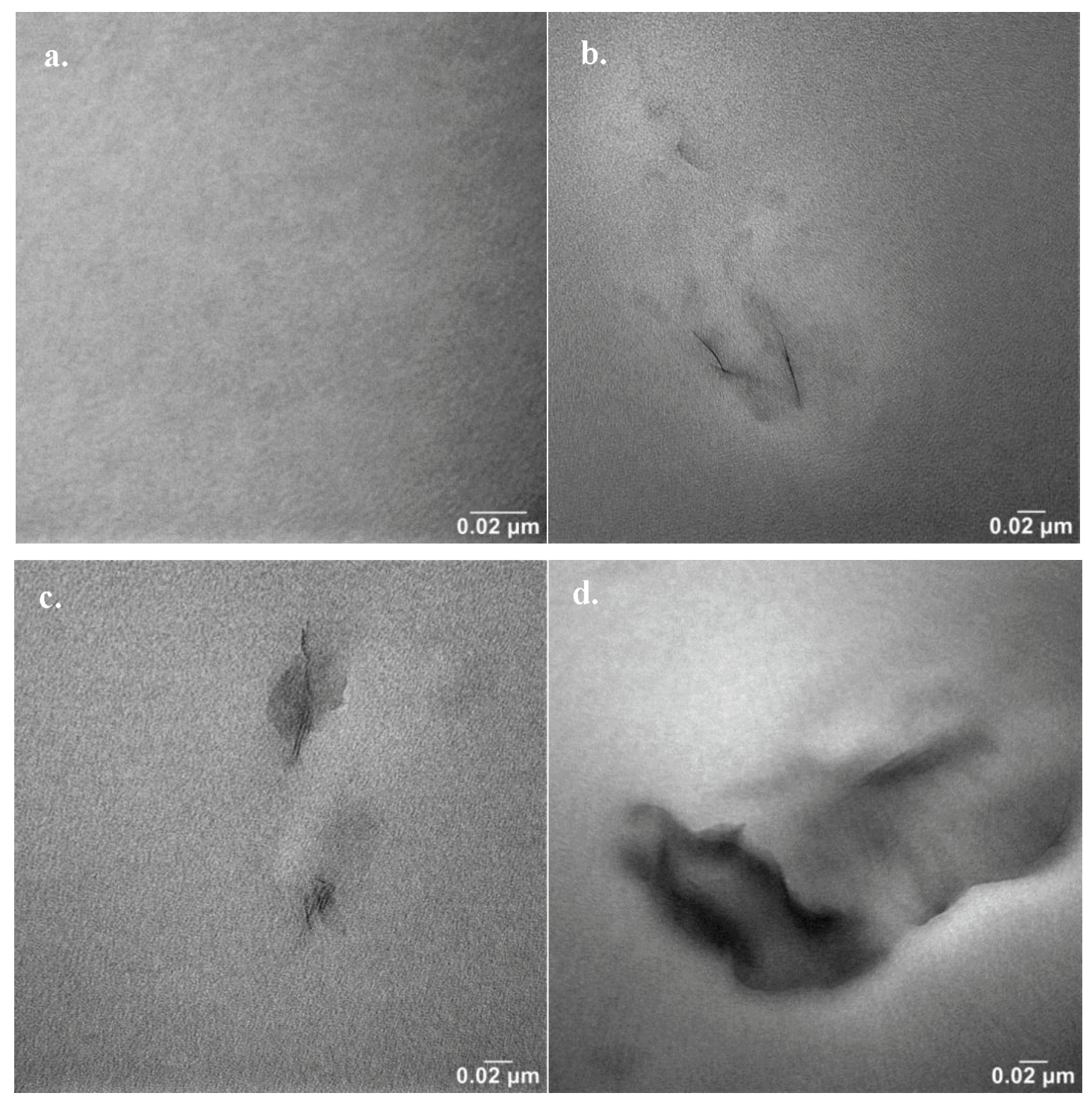

Fig. 4. TEM micrographs: (a) the unfilled P3HB and its nanobiocomposites containing, (b) 1 wt. $\%$ of Cloisite $30 \mathrm{~B}$, (c) 1 wt. \% of Cloisite $30 \mathrm{~B}$ and 1 wt. \% of PU-MDI and (d) 1 wt. \% of Cloisite 30B and 5 wt. \% PU-MDI (designated: P3HB-1, P3HB-1.1 and P3HB-1.5, respectively)

Inspection of this picture reveals a homogeneous dispersion of the clay platelets throughout the matrix and in the nanometer-scale level. Extensive TEM observations revealed a coexistence of silicate particles in the intercalated and exfoliated state. The montmorillonite layers were well dispersed in the matrix as random delaminated nanosheets, indicating mainly the exfoliating structure. Figures $4 \mathrm{c}$ and $\mathrm{d}$ show the TEM images of the nanocomposites with 1 wt. $\%$ of Cloisite $30 \mathrm{~B}$ and 1 and 5 wt. $\%$ of PU-MDI, respectively. Its TEM image at high magnification clearly demonstrates intercalated/partially exfoliated clay structure with some amount of delaminated nanosheets indicative of incomplete exfoliation mainly made of intercalated structure and few exfoliated particles. The main common observation for Fig. 4c and $\mathrm{d}$ is that they all show a nanoscale dispersed morphology independent on polyurethane concentration identified by the presence of single clay nanosheets without appearance of any agglomeration. Exfoliated clays constitute the major structure evidenced from single clay nanoplatelets and absence of tactoids.

SEM micrographs were obtained from impact fractured surfaces near the crack tip and are shown in Fig. 5.

The surface of the unmodified $\mathrm{P} 3 \mathrm{HB}$ shown in Fig. 5a is mostly flat, smooth and glassy with a small amount of plastic deformation. Based on these features, the matrix can be classified as fragile and glassy polymeric materials. In Fig. 5b, the surface of P3HB modified with 1 wt. \% of Cloisite 30B nano- 

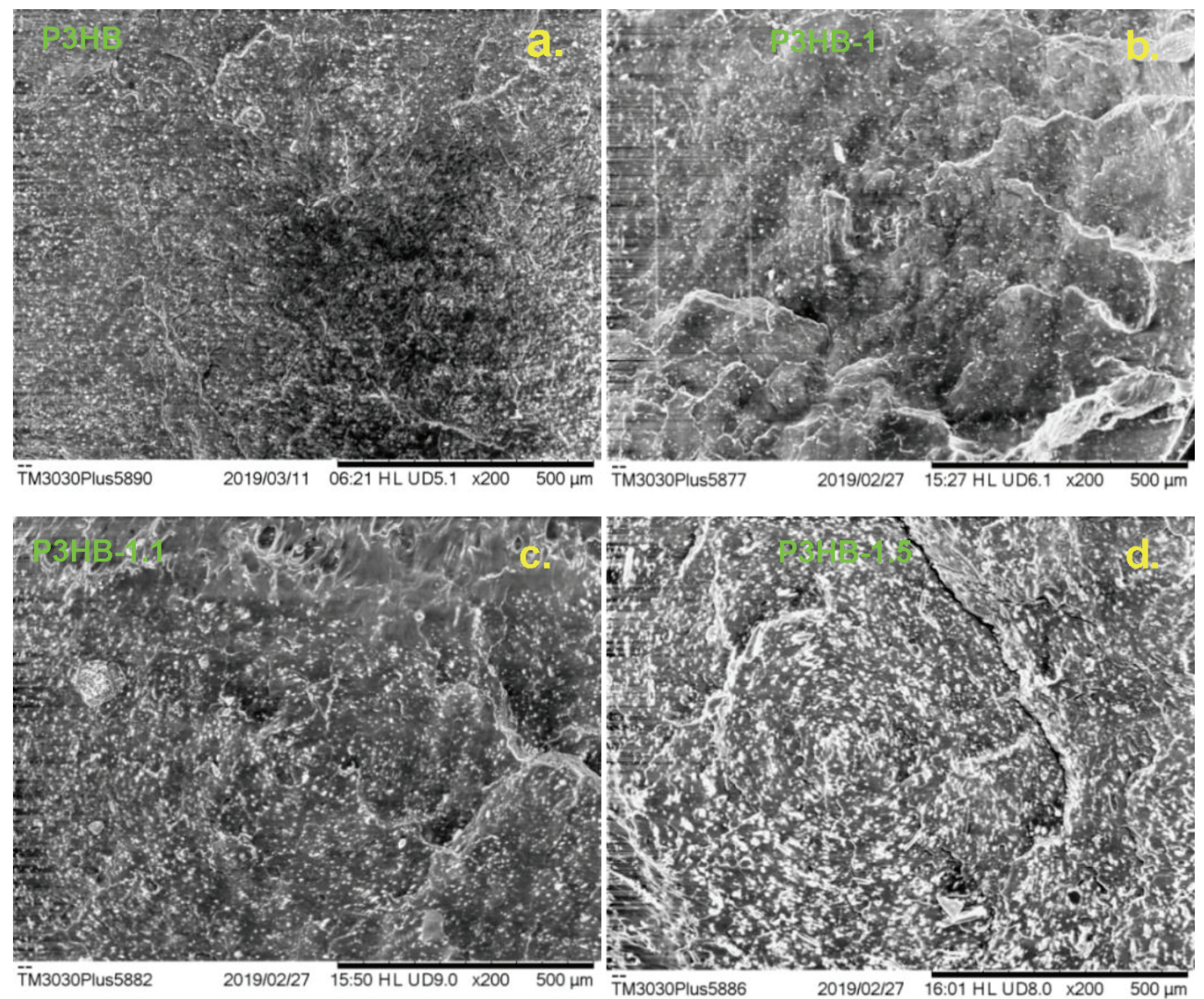

Fig. 5. Structure micrographs of: (a) the unfilled P3HB and its nanobiocomposites containing, (b) 1 wt. \% Cloisite 30B, and (c) 1 wt. \% Cloisite 30B and 1 wt. \% PU-MDI and (d) 1 wt. \% Cloisite $30 \mathrm{~B}$ and $5 \mathrm{wt}$ \% PU-MDI

(designated: P3HB, P3HB-1, P3HB-1.1 and P3HB-1.5, respectively) made using a scanning electron microscope

bent (P3HB-1) is shown. Compared to matrix micrographs, the surface of P3HB-1 is rather rough with a continuous continuous phase along with large smooth areas associated with plasticity in the polymer matrix. Rough and layered areas are assigned a phase rich in nanobent, while smooth areas are assigned a phase rich in P3HB. Cavitation-specific areas are also visible.

Micrographic analysis of hybrid nanobiocomposites confirms very well the dispersion and deposition of Cloisite 30B in P3HB / PU-MDI systems. It can also be observed that all micrographs of hybrid nanobiocomposites (Fig. 5c and d) are very similar and have a rough structure. The obtained images are like the result of the unfilled P3HB (Fig. 5a) and previously obtained micrographs for two-component composites, i.e., for P3HB modified only with Cloisite 30B (Fig. 5b). The images confirm the features of the polymers and nanofillers themselves. It can be seen that the nanoparticles adhere well to the polymer matrix are dispersed homogenousely in the polymer mixture and there are no agglomerates of particles. These features are more visible for hybrid nanobiocomposites containing a higher amount of PU (5 wt. \%).

\section{Thermal properties of the resulting hybrid nanobiocomposites}

In order to examine the thermal stability of the obtained nanobiocomposites, thermogravimetric tests were carried out. The TGA measurement results are given in Table 1 and in Fig. 6.

Table 1. Interpretation of the TG and DTG curves of $\mathrm{P} 3 \mathrm{HB}$ and nanocomposites based on $\mathrm{P} 3 \mathrm{HB}$ and Cloisite $30 \mathrm{~B}$ and PU-MDI recorded at heating rate of $10^{\circ} \mathrm{C} \cdot \mathrm{min}^{-1}$ in nitrogen

\begin{tabular}{|l|c|c|c|c|}
\hline & P3HB & P3HB-1 & P3HB-1.1 & P3HB-1.5 \\
\hline$T_{1 \%}$ & 232 & 237 & 251 & 253 \\
\hline$T_{2 \%}$ & 245 & 255 & 258 & 260 \\
\hline$T_{5 \%}$ & 256 & 264 & 264 & 268 \\
\hline$T_{10 \%}$ & 263 & 269 & 269 & 273.5 \\
\hline$T_{20 \%}$ & 268 & 274 & 274 & 278 \\
\hline$T_{50 \%}$ & 277 & 280 & 280.5 & 284 \\
\hline Temp.range & $240-320$ & $240-320$ & $240-300$ & $245-300$ \\
\hline$T_{\text {max }}\left[{ }^{\circ} \mathrm{C}\right]$ & 278 & 281 & 282 & 286 \\
\hline$\Delta m[\%]$ & 98.57 & 98.55 & 98.5 & 94.58 \\
\hline $\begin{array}{l}\text { Remaining mass } \\
\text { at. } 400{ }^{\circ} \mathrm{C}[\%]\end{array}$ & 1.33 & 1.45 & 1.50 & 5.42 \\
\hline
\end{tabular}



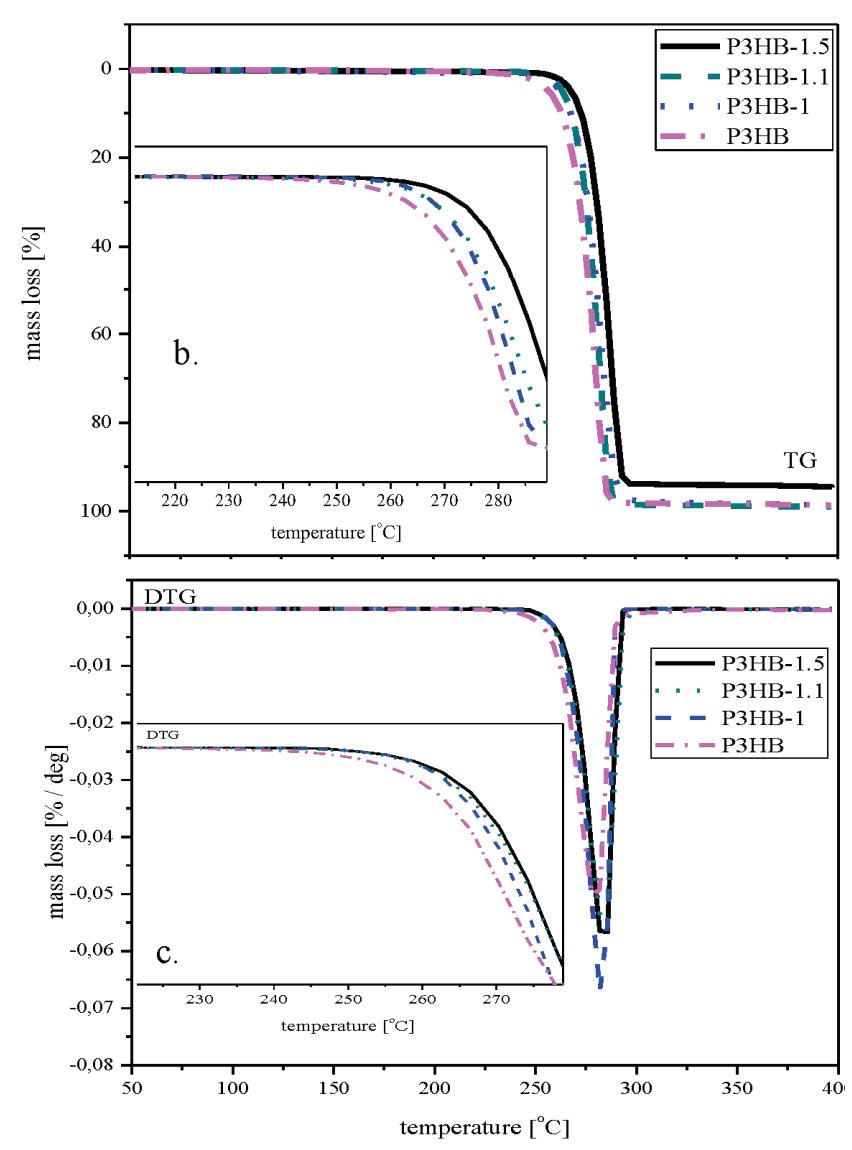

Fig. 6. The TGA thermograms of $\mathrm{P} 3 \mathrm{HB}$ and its nanobiocomposites containing $1 \mathrm{wt} \%$ of nanoclay and 1 or $5 \mathrm{wt}$ \% PU-MDI indicated as P3HB, P3HB-1, P3HB-1.1, P3HB-1.5, respectively. Parts $b$ and $c$ (insert) show an enlargement of the temperature diagnostic area

TGA analysis of nanobiocomposites showed that the thermal stability all of them is higher than that of the unfilled P3HB. The addition of Cloisite 30B into the P3HB matrix causes the degradation temperature increases by $5-10{ }^{\circ} \mathrm{C}$ depending on the decomposition stage, e.g., $2 \%$ mass loss occurs at $245^{\circ} \mathrm{C}$ and $255^{\circ} \mathrm{C}$ for the unfilled P3HB and P3HB-1, respectively (Table 1). At higher mass losses, differences are smaller, e.g., for $10 \%$ mass loss - they are 263 and $269{ }^{\circ} \mathrm{C}$ for P3HB and P3HB-1, respectively. The addition of Cloisite 30B into the $\mathrm{P} 3 \mathrm{HB}$ matrix causes the degradation temperature increases by $5-10{ }^{\circ} \mathrm{C}$ depending on the decomposition stage, e.g., $2 \%$ mass loss occurs at $245{ }^{\circ} \mathrm{C}$ and $255{ }^{\circ} \mathrm{C}$ for the unfilled $\mathrm{P} 3 \mathrm{HB}$ and $\mathrm{P} 3 \mathrm{HB}-1$, respectively (Table 1). At higher mass losses, differences are smaller, e.g., for $10 \%$ mass loss - they are 263 and $269{ }^{\circ} \mathrm{C}$ for P3HB and P3HB-1, respectively. The addition of PU-MDI causes a further increase in the degradation temperature of the nanobiocomposites. A similar effect is observed upon an increase the content of PU-MDI in the nanobiocomposites from 1 to $5 \mathrm{wt}$ \%.
This is most evident in the $1 \%$ mass loss that occurs at 232, 237, 251 and $253{ }^{\circ} \mathrm{C}$ for P3HB, P3HB-1, P3HB-1.1 and P3HB-1.5, respectively.

The decomposition of all materials, both the unfilled $\mathrm{P} 3 \mathrm{HB}$ and its nanobiocomposites, takes place in one stage, which occurs in the temperature range from 240 to $320{ }^{\circ} \mathrm{C}$. The mass loss is about $98.5 \%$ for P3HB, P3HB-1, P3HB-1.1 and 95.5\% for P3HB-1.5. The mass of residues at $400{ }^{\circ} \mathrm{C}$ is low and the increased amount of residue (5.5 wt. \%) for P3HB-1.5 is associated with the formation of non-volatile structures composed of condensed aromatic rings.

Thermal analysis of obtained nanobiocomposites and polymer matrix was also carried out using the differential scanning calorimetry (DSC). Figures 7-9 show the experimental heat flow rate versus temperature obtained during heating (Figs. 7 and 8) at rate $10{ }^{\circ} \mathrm{C} \cdot \mathrm{min}^{-1}$ from $-90{ }^{\circ} \mathrm{C}$ to $195{ }^{\circ} \mathrm{C}$ and after prior cooling under the same conditions (Fig. 9). The analysis of heat flow (the qualitative thermal analysis) rate

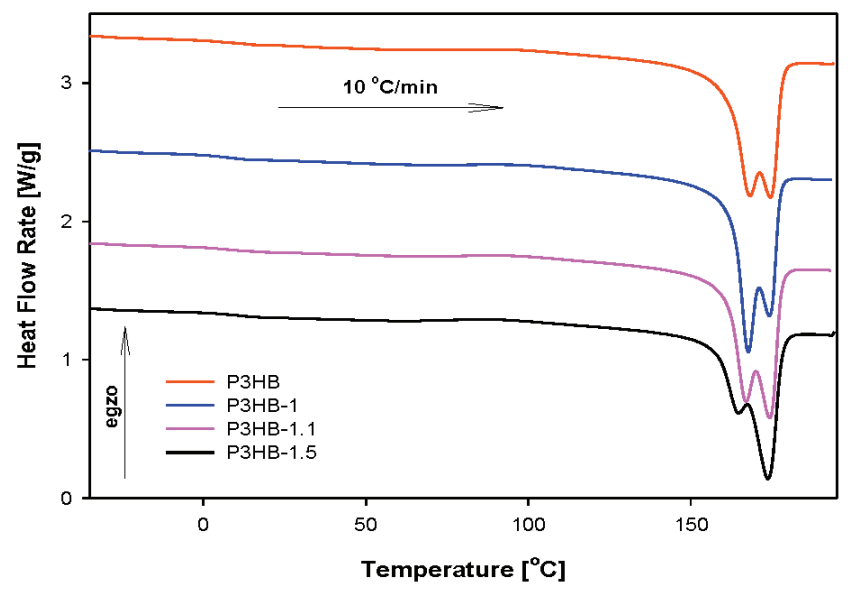

Fig. 7. Dependence of heat flow rate of nanocomposites on temperature under heating

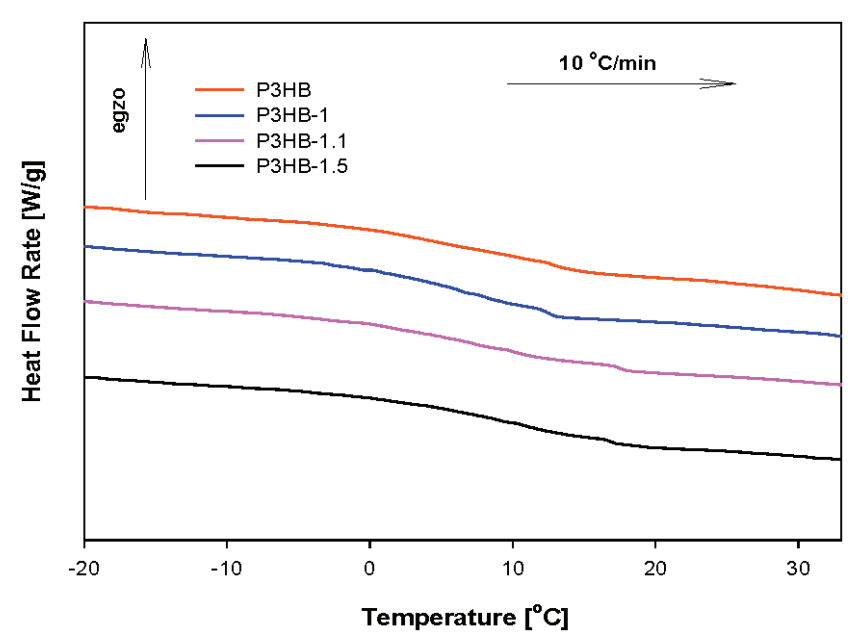

Fig. 8. The enlargement of the glass ransition region from Fig. 7 


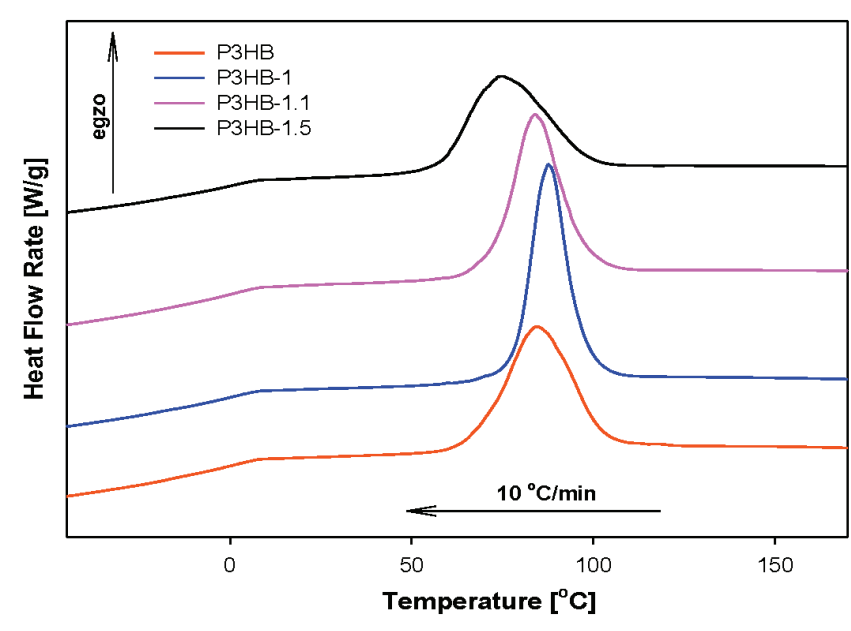

Fig. 9. Dependence of heat flow rate of nanobiocomposites on temperature under a cooling at rate of $10^{\circ} \mathrm{C} \cdot \mathrm{min}^{-1}$ in the range of $195^{\circ} \mathrm{C}$ to $-90^{\circ} \mathrm{C}$ by DSC

was applied for the unfilled P3HB matrix and its nanobiocomposites. All parameters of phase transitions were estimated and listed in Table 2 . The change of heat capacity, $\Delta C_{p}$, and the temperature of glass transition, $T_{g}$, were established from the study of the glass transition region under heating and the heat of fusion, $\Delta H_{f}$, and the melting temperature, i.e., the onset melting temperature, $T_{m \text { (onset) }}$, and the peak melting temperature, $T_{m \text { (peak) }}$, were also estimated based on analysis of the melting region. The heat of crystallization, $\Delta H_{c}$, and the crystallization temperature, $T_{c}$, were analysed under the cooling.

It can be observed that values of the $T_{g}, T_{m}$ and $T_{c}$ decreased with addition the Cloisite $30 \mathrm{~B}$ and next polyurethane and with increasing content of the last one. The biggest change of parameters were observed between P3HB-1.5 and the unfilled P3HB. The change of $\Delta C_{p}, T_{g}$ and $T_{c \text { (onset) }}$ decreased about $6 \mathrm{~J} \cdot \mathrm{mol}^{-1} \cdot{ }^{\circ} \mathrm{C}^{-1}$, $9{ }^{\circ} \mathrm{C}$ and $15.6{ }^{\circ} \mathrm{C}$, respectively. The decrease of $T_{g}$ of nanobiocomposites is linking with the plasticizing effect of the introduced fillers. Moreover, the influence of additives in the P3HB matrix was also noticed based on $\Delta H_{f}$ and $\Delta H_{c}$. The decrease of values were $980 \mathrm{~J} \cdot \mathrm{mol}^{-1}$ and $1830 \mathrm{~J} \cdot \mathrm{mol}^{-1}$, respectively. The $T_{m \text { (onset) }}$ and $T_{m \text { (peak) }}$ were also estimated. The multipeak was observed in the melting region. It was probably linking with a different thickness of lamellar crystal. The decrease of $T_{m \text { (onset) }}$ between P3HB and P3HB-1.5 was about $9{ }^{\circ} \mathrm{C}$ and $T_{m \text { (peak) }}$ were decreased $\sim 22{ }^{\circ} \mathrm{C}$ and $\sim 14{ }^{\circ} \mathrm{C}$, respectively for first and second endothermic peaks in the multipeak melting process. The decrease of $T_{m}$ and simultaneous increase of the degradation temperature together with the increase of the fillers content in the nanobiocomposites have a satisfactory

Table 2. Comparison of thermal parameters of the unfilled P3HB and its nanobiocomposites

\begin{tabular}{|c|c|c|c|c|c|c|c|c|}
\hline Sample & $\begin{array}{c}\Delta C_{p}{ }^{*} \\
{\left[\mathrm{~J} \cdot \mathrm{mol}^{-1} \cdot{ }^{\circ} \mathrm{C}^{-1}\right]}\end{array}$ & $\begin{array}{c}T_{g} \\
{\left[{ }^{\circ} \mathrm{C}\right]}\end{array}$ & $\begin{array}{c}\Delta H_{f}^{*} \\
{\left[\mathrm{~kJ} \cdot \mathrm{mol}^{-1}\right]}\end{array}$ & $\begin{array}{c}T_{m \text { (onset) }} \\
{\left[{ }^{\circ} \mathrm{C}\right]}\end{array}$ & $\begin{array}{c}T_{m(\text { peak1) }} \\
{\left[{ }^{\circ} \mathrm{C}\right]}\end{array}$ & $\begin{array}{c}T_{m(\text { peak } 2)} \\
{\left[{ }^{\circ} \mathrm{C}\right]}\end{array}$ & $\begin{array}{c}\Delta H_{c}^{*} \\
{[\mathrm{~kJ} / \mathrm{mol}]}\end{array}$ & $\begin{array}{c}T_{c \text { (onset) }} \\
{\left[{ }^{\circ} \mathrm{C}\right]}\end{array}$ \\
\hline P3HB & 13.96 & 7.7 & 7.91 & 161.4 & 168.0 & 174.5 & 7.64 & 104.8 \\
\hline P3HB-1 & 14.91 & 7.5 & 8.15 & 157.7 & 167.7 & 174.3 & 8.21 & 100.7 \\
\hline P3HB-1.1 & 16.63 & 3.9 & 9.21 & 157.0 & 153.1 & 165.4 & 7.68 & 91.6 \\
\hline P3HB-1.5 & 7.89 & -1.0 & 6.93 & 152.2 & 145.9 & 160.2 & 5.81 & 89.2 \\
\hline
\end{tabular}

* The values were calculated based on following the molar mass of repeating units: $\mathrm{M}_{\mathrm{P} 3 \mathrm{HB}}=86.09 \mathrm{~g} / \mathrm{mol}, \mathrm{M}_{\mathrm{P} 3 \mathrm{HB}-1}=87 \mathrm{~g} / \mathrm{mol}$, $\mathrm{M}_{\mathrm{P} 3 \mathrm{HB}-1.1}=90.72 \mathrm{~g} / \mathrm{mol}, \mathrm{M}_{\mathrm{P} 3 \mathrm{HB}-1.5}=100.76 \mathrm{~g} / \mathrm{mol}$.
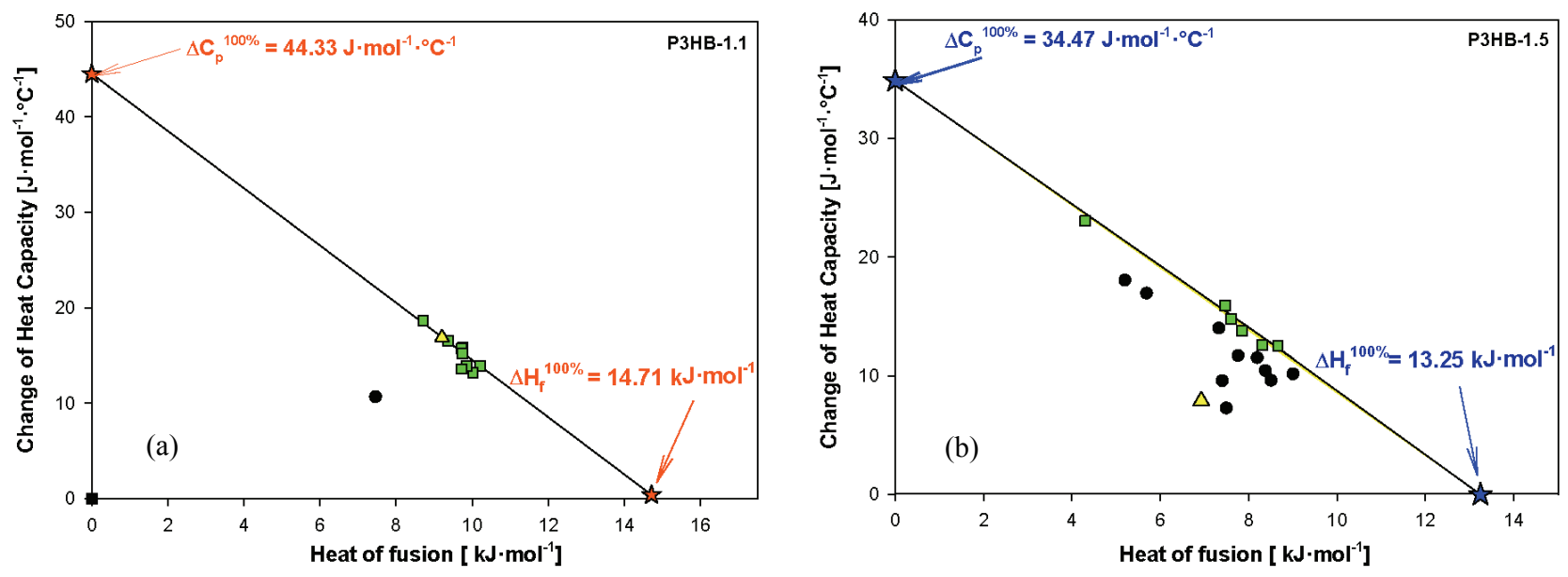

Fig. 10. The dependence of $\Delta C_{p}$ at $T_{g}$ on $\Delta H_{f}$ of the nanobiocomposites: (a) P3HB-1.1, (b) P3HB-1.5 
effect on the processing window of the extrusion process. The biggest different between the temperature of degradation and $T_{m \text { (onset) }}$ was observed for the P3HB-1.5 nanocomposite and was $100.8{ }^{\circ} \mathrm{C}$.

The thermal history was alsso studied. Results obtained based on the different cooling rates were shown graphically in Fig. 10 as the change of heat capacity versus the heat of fusion.

Hereby, it should be noted that changes of heat capacity were established using the qualitative thermal analysis. The all points show the experimental measurements in Fig. 10. The solid straight line was estimated for the green squares $\left(R^{2}=0.9681\right)$ and determined between the full amorphous and full crystalline P3HB-1.1 marked by red stars. The mobile amorphous phase and the crystalline phase give the linear behaviour between the $\Delta H_{f}$ and $\Delta C_{p}$. The change of heat capacity for fully amorphous P3HB-1.1, $\Delta C_{p}^{100 \%}$, equals $42.6 \mathrm{~J} \cdot \mathrm{mol}^{-1} \cdot{ }^{\circ} \mathrm{C}^{-1}$ and the heat of fusion for fully crystalline P3HB-1.1, $\Delta H_{f}^{100 \%}$, equals $12.70 \mathrm{~kJ} \mathrm{~mol}^{-1}$. Most semicrystalline polymeric materials have three phases in the solid state: the crystalline phase (c), the mobile amorphous fraction (a) and the rigid amorphous fraction (RAF). The points on the solid straight line (the green squares) are characteristic for twophase model. The points outside of the solid line are shown the three phase-model (the black circles). The dependence of the degree of amorphous phase, $W_{a}$, on the degree of crystallinity, $W_{c}$, of P3HB-1.1 was shown in Fig. 11 with different thermal history. The data from Fig. 10a were recalculated to $W_{a}$ and $W_{c}$ according to $W_{a}=\Delta C_{p} / \Delta C_{p}^{100 \%}$, and $W_{c}=\Delta H_{f} / \Delta H_{f}^{100 \%}$. The degree of crystallinity $\left(W_{c}\right)$ was determined as the ratio between the experimental $\Delta H_{f}$ of the semicrystalline nanobiocomposite and $\Delta H_{f}$ of the fully crystalline sample $\left(\Delta H_{f}^{100 \%}\right)$.

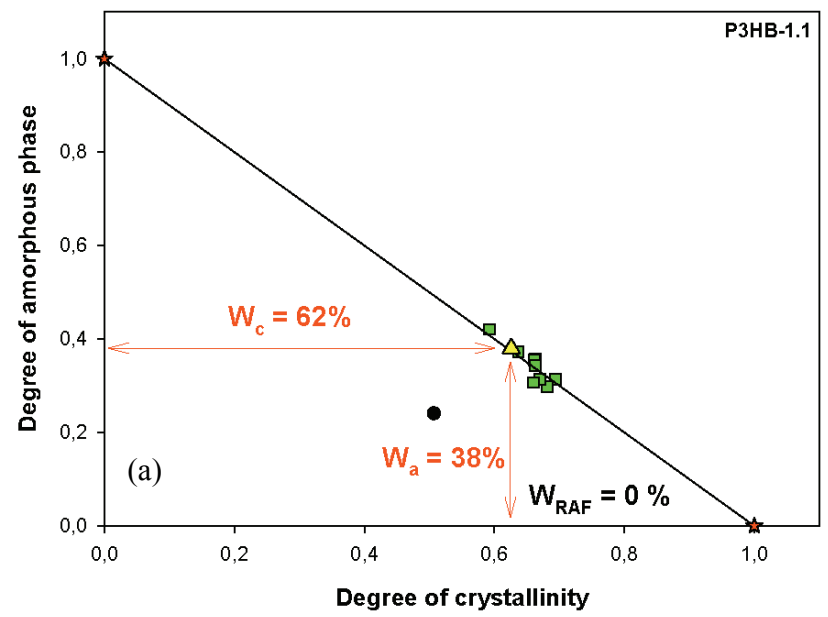

The mobile amorphous fraction $\left(W_{a}\right)$ was defined as a relation of $\Delta C_{p}$ measured at $T_{g}$ of the semicrystalline nanobiocomposite to $\Delta C_{p}$ of the fully amorphous sample $\left(\Delta C_{p}^{100 \%}\right)$. The $\Delta C_{p}^{100 \%}$ of P3HB-1.1 equals $44.33 \mathrm{~J} \cdot \mathrm{mol}^{-1} \cdot{ }^{\circ} \mathrm{C}^{-1}$, and the heat of fusion for the fully crystalline nanobiocomposite equals $14.71 \mathrm{~kJ} \cdot \mathrm{mol}^{-1}$. The triangle yellow point was also plotted in Figs. 10a and 11a. The data of $\Delta C_{p}$ and $\Delta H_{f}$ were obtained during the heating at $10{ }^{\circ} \mathrm{C} \cdot \mathrm{min}^{-1}$ after the cooling of the P3HB-1.1 nanobiocomposite at constant rate of $10^{\circ} \mathrm{C} \cdot \mathrm{min}^{-1}$. The triangle point in Fig. 11a represents the two-phase model. The P3HB-1.1 contains $62 \%$ of the amorphous phase and $38 \%$ of the crystalline phase. The rigid amorphous fraction is not observed. The triangle point is on the straight line.

Table 3. Characterization of phase contents for the unfilled P3HB and its nanobiocomposites

\begin{tabular}{|l|c|c|c|c|c|}
\hline \multicolumn{1}{|c|}{ Sample } & $\begin{array}{c}\Delta C_{p}^{100 \%} \\
{\left[\mathrm{~J} \cdot \mathrm{mol}^{-1} \cdot{ }^{\circ} \mathrm{C}^{-1}\right]}\end{array}$ & $\begin{array}{c}\Delta H_{f}^{100 \%} \\
{\left[\mathrm{~kJ} \cdot \mathrm{mol}^{-1}\right]}\end{array}$ & $\begin{array}{c}W_{c} \\
{[\%]^{*}}\end{array}$ & $\begin{array}{c}W_{a} \\
{[\%]^{*}}\end{array}$ & $\begin{array}{c}W_{\mathrm{RAF}} \\
{[\%]^{*}}\end{array}$ \\
\hline P3HB & 42.20 & 12.48 & 63 & 33 & 4 \\
\hline P3HB-1 & 42.60 & 12.70 & 65 & 35 & 0 \\
\hline P3HB-1.1 & 44.33 & 14.71 & 62 & 38 & 0 \\
\hline P3HB-1.5 & 34.47 & 13.25 & 52 & 23 & 25 \\
\hline
\end{tabular}

* Result obtained based on the analysis nanobiocomposites during heating (Figs. 7 and 8 ) at rate of $10 \mathrm{~K} \cdot \mathrm{min}^{-1}$ from $-90{ }^{\circ} \mathrm{C}$ to $195^{\circ} \mathrm{C}$ and after prior cooling in the same conditions (Fig. 9).

The other nanobiocomposites presented in Fig. 7 were also studied in this same way. The thermal history of all samples were used in order to establish $\Delta C_{p}^{100 \%}$ and $\Delta H_{f}^{100 \%}$. Obtained results were listed in Table 3. It can be observed that only P3HB-1.5 has got a rigid amorphous fraction. This example was illustrated in Figs. $10 \mathrm{~b}$ and $11 \mathrm{~b}\left(R^{2}=0.986\right)$. The

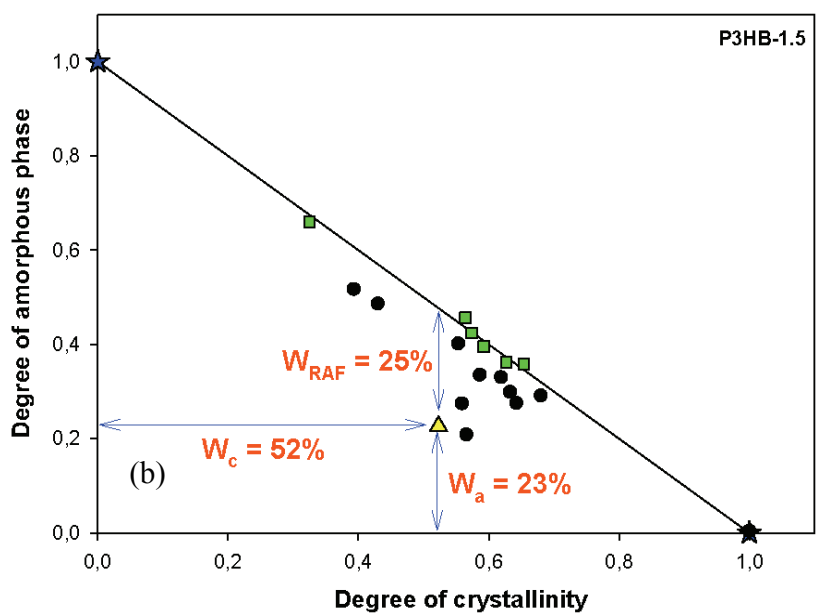

Fig. 11. Dependence of the amorphous fraction as a function of the degree of crystallinity of the semicrystalline: (a) P3HB-1.1, (b) P3HB-1.5 
P3HB and P3HB-1 samples were described in [7]. In this paper, the results from the earlier article was used as reference to the new-obtained nanobiocomposites contain polyurethane as filler.

Figure $10 \mathrm{~b}$ shows the analysis of thermal history of the P3HB-1.5. The dependence of $\Delta C_{p}$ at $T_{g}$ on $\Delta H_{f}$ was estimated like for the P3HB-1.1. Based on this analysis, the contents of crystalline phase $\left(W_{c}\right)$, the mobile amorphous fraction $\left(W_{a}\right)$ and the rigid amorphous fraction $\left(W_{\mathrm{RAF}}\right)$ were determined. The triangle point in Fig. 11b illustrates the result obtained based on the analysis nanocomposites during heating at rate of $10 \mathrm{~K} / \mathrm{min}$ from $-90{ }^{\circ} \mathrm{C}$ to $195{ }^{\circ} \mathrm{C}$ and after prior cooling in the same conditions. The content of $W_{c}, W_{a}$ and $W_{\text {RAF }}$ were estimated as 52,23 and $25 \%$, respectively.

\section{Mechanical properties of the resulting hybrid nanobiocomposites}

Nanobiocomposites obtained as a result of the P3HB modification were tested for mechanical properties. During the preparation of moulders for mechanical tests, higher thermal stability of the P3HB nanobiocomposites and a wider temperature range of processing were noticed, compared to the unfilled $\mathrm{P} 3 \mathrm{HB}$. At the same processing temperature the viscosity of the unfilled $\mathrm{P} 3 \mathrm{HB}$ was lower compared to nanobiocomposites. It was the reason for the appearance of small, very thin outflows, indicating a very low viscosity of the material. This was also the cause of higher fluctuations in the recorded material pressure in the mold cavity. The qualitative values of the samples (esthetics, production quality) were definitely better for hybrid nanobiocomposites. Minimal collapse of the material on the surface of the P3HB moulders and a lack of their homogeneity were shown, whereas the moulders of P3HB-1.1 and P3HB-1.5 were completely homogeneous and smooth.

First, moulders of $\mathrm{P} 3 \mathrm{HB}$ and its nanobiocomposites were subjected to static tensile test. Nanobiocomposites show differences in properties relative to the unfilled P3HB. The results of tensile tests of P3HB and its nanobiocomposites are presented in Fig. 12 and in Table 4. The increase in longitudinal modulus $\left(E_{t}\right)$ of all produced nanobiocomposites compared to the unfilled P3HB is particularly important. The unfilled P3HB has the smallest modulus value of $2.83 \mathrm{GPa}$.

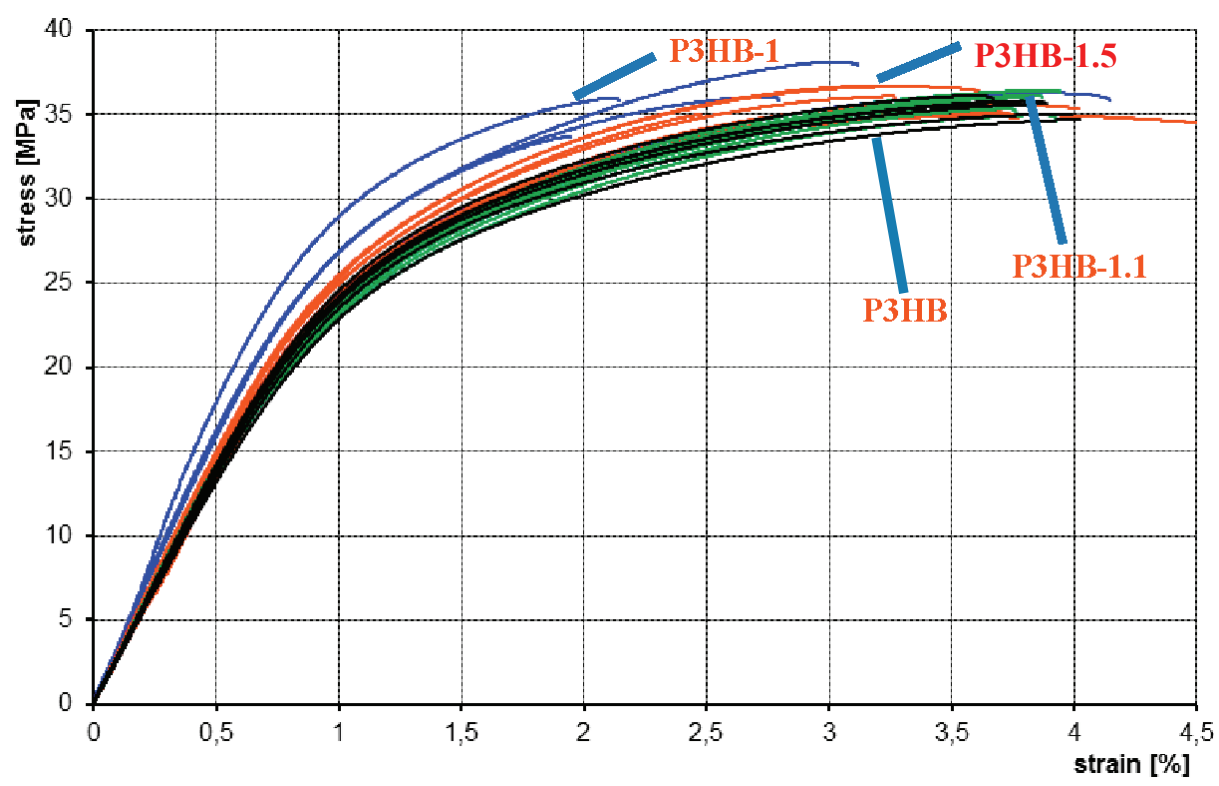

Fig. 12. Tensile curves recorded for the unfilled P3HB and its hybrid nanobiocomposites

Table 4. Static tensile test results, average values are given for representative samples

\begin{tabular}{|l|c|c|c|c|c|c|c|}
\hline \multicolumn{1}{|c|}{ Sample } & $E_{t}{ }^{\mathrm{a}}[\mathrm{GPa}]$ & $\sigma_{Y}{ }^{\mathrm{b}}[\mathrm{MPa}]$ & $\varepsilon_{Y}{ }^{\mathrm{c}}[\%]$ & $\sigma_{M}{ }^{\mathrm{d}}[\mathrm{MPa}]$ & $\varepsilon_{M}{ }^{\mathrm{e}}[\%]$ & $\sigma_{B}{ }^{\mathrm{f}}[\mathrm{MPa}]$ & $\varepsilon_{t B}{ }^{\mathrm{g}}[\%]$ \\
\hline P3HB & $2.83 \pm 0.05$ & $35.50 \pm 0.33$ & $3.79 \pm 0.15$ & $35.47 \pm 0.52$ & $3.80 \pm 0.18$ & $21.02 \pm 0.11$ & $4.00 \pm 0.21$ \\
\hline P3HB-1 & $3.31 \pm 0.20$ & $35.95 \pm 1.81$ & $2.46 \pm 0.51$ & $36.01 \pm 1.57$ & $2.74 \pm 0.16$ & $18.33 \pm 0.52$ & $3.29 \pm 0.20$ \\
\hline P3HB-1.1 & $2.93 \pm 0.08$ & $35.62 \pm 0.61$ & $3.75 \pm 0.15$ & $35.66 \pm 0.50$ & $3.67 \pm 0.20$ & $21.97 \pm 0.11$ & $3.97 \pm 0.21$ \\
\hline P3HB-1.5 & $3.00 \pm 0.19$ & $35.85 \pm 0.71$ & $3.45 \pm 0.21$ & $35.65 \pm 0.74$ & $3.32 \pm 0.28$ & $24.67 \pm 0.12$ & $4.06 \pm 0.17$ \\
\hline
\end{tabular}

a: $E_{t}-$ Young's modulus, b: $\sigma_{Y}$ - yield stress, c: $\varepsilon_{Y}$ - elongation (relative) at yield point, d: $\sigma_{M}$ - tensile strength, e: $\varepsilon_{M}-$ elongation (relative) at maximum stress, f: $\sigma_{B}$-stress (relative) at sample break, g: $\varepsilon_{t B}$ - elongation (relative) at break. 
An addition of 1 wt. \% nanoclay (P3HB-1) makes $E_{t}$ increases to $3.31 \mathrm{GPa}$. In turn, the addition of nanoclay and PU-MDI also increases $E_{t}$ of P3HB-1.1 and P3HB-1.5 compared to the unfilled P3HB but these values are lower than for P3HB-1; 2.93 and $3.00 \mathrm{GPa}$ for P3HB-1.1 and P3HB-1.5, respectively. The tensile strength of the unfilled $\mathrm{P} 3 \mathrm{HB}$ and all its nanobiocomposites is similar and it is in the range of $35.50-35.95 \mathrm{MPa}$. The values of tensile strength of individual materials change analogously to the values of their modulus of elasticity.

Elongation at break decreases for nanobiocomposites containing $1 \mathrm{wt}$ \% Cloisite 30B (P3HB-1) relative to the unfilled $\mathrm{P} 3 \mathrm{HB}$ and it is 3.29 and $4.00 \%$, respectively. The addition of PU-MDI means that the elongation at break increases again and at $5 \mathrm{wt} \%$. PU-MDI content is $4.06 \%$. Thus, the addition PU-MDI is beneficial because it influences the increase the elongation at break which decreases in the presence of nanoclay.

Table 5. Impact tensile strength for the unfilled P3HB and its nanobiocomposites

\begin{tabular}{|l|c|c|}
\hline \multicolumn{1}{|c|}{ Sample } & $\begin{array}{c}\text { Absorption energy } \\
{[\%]}\end{array}$ & $\begin{array}{c}\text { Impact tensile strength, } \\
\operatorname{Re}\left[\mathrm{kJ} / \mathrm{m}^{2}\right]\end{array}$ \\
\hline P3HB & $5.52 \pm 0.45$ & $10.72 \pm 0.82$ \\
\hline P3HB-1 & $5.46 \pm 0.38$ & $11.23 \pm 1.11$ \\
\hline P3HB-1.1 & $4.96 \pm 0.33$ & $11.68 \pm 0.75$ \\
\hline P3HB-1.5 & $6.42 \pm 0.52$ & $9.92 \pm 1.29$ \\
\hline
\end{tabular}

In turn, impact tensile strength grows slightly after an addition of 1 wt. \% nanoclay into the unfilled $\mathrm{P} 3 \mathrm{HB}$ (Table 5). The presence of second filler PU-MDI causes a further slight increase of it. After inserting 5 wt. \% of PU-MDI a decrease in impact tensile strength is observed. However, the decrease is insignificant and amounts to max. $7.5 \%$, compared to the unfilled P3HB.

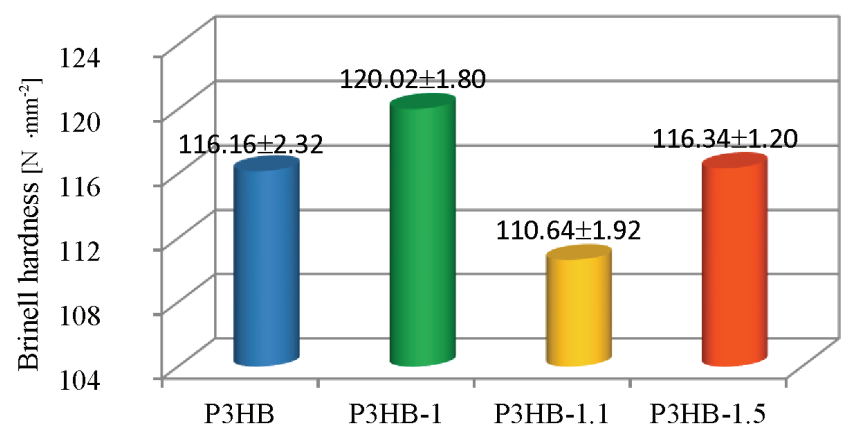

Fig. 13. Average values of Brinell hardness for the unfilled P3HB and its nanobiocomposites
The average Brinell hardness values of the unfilled $\mathrm{P} 3 \mathrm{HB}$ and its nanobiocomposites were just a positioned in Fig. 13. In this case, an increase in the hardness for the P3HB-1 at about $4 \mathrm{~N} \cdot \mathrm{mm}^{-2}$ compared to the unfilled P3HB has been noticed. The addition of PU-MDI causes a decrease in hardness by about $4.7 \%$, but the increase in the content of PU-MDI (P3HB-1.5) means that the hardness also increases and is basically slightly higher than the hardness of the unfilled P3HB.

\section{Discussion}

Hybrid biocomposites based on $\mathrm{P} 3 \mathrm{HB}$, organic nanoclay Cloisite 30B and linear polyurethane have the proved nanostructure with a presence of intercalated structure and predominance of exfoliated structure. Such high dispersion degree was possible because the favorable interactions between the $\mathrm{P} 3 \mathrm{HB}$ functional groups and those on the clay took place for a longer time, i.e., formation of hydrogen bonds between ester groups of $\mathrm{P} 3 \mathrm{HB}$ and hydroxyl groups of montmorillonite. Furthermore, the shear melt viscosity became high by the added viscous linear polyurethane that improved delamination and breakdown of clay tactoids and helped insertion of both types of polymer molecules into the clay stacks. Moreover, the exfoliating structure means that the motion of the polymer chains is necessary for their diffusion into clay galleries [4]. The observations of TEM are consistent with the SAXS results. In SAXS diffractograms, the coexistence of both intercalated and exfoliated structures was observed. Low intensity of the peak in the XRD spectra of the nanocomposite around $1.6^{\circ}$ of $2 \theta$ means that the exfoliated structure is the preponderant one.

The morphology of $\mathrm{P} 3 \mathrm{HB}$ and its nanobiocomposites, investigated by SEM, revealed the homogeneous rough structure of the nanoparticles evenly distributed throughout the entire volume of the three-component nanobiocomposite. The presence of cavitation-specific areas indicates that strain is concentrated during the cracking process of the samples. It is widely accepted that the occurrence of the ductile shear in the polymer matrix predicts the increase in its mechanical properties. All of the above-noticeable characteristic features indicate that the selected modifiers seem to be compatible with the P3HB matrix used and affect the P3HB matrix reinforcement favorably.

Nanobiocomposites obtained as a result of the P3HB modification have higher thermal stability and a wider temperature range of processing compared to 
the unfilled P3HB. As predicted based on morphology, hybrid composites show better mechanical properties. The presence of the second filler influenced the deterioration of Young's modulus, yield stress and tensile strength. It is connected with the plasticizing effect caused by the presence of linear polyurethane. Nevertheless, the values of mentioned properties stayed better, relative to the unfilled P3HB. In the case of the rest of tested mechanical properties such as elongation (relative) at yield point, elongation (relative) at maximum stress, stress (relative) at sample break and elongation (relative) at break only positive influence of on PU-MDI additive is observed and even moderating the negative impact of introducing nanoclay.

The copacetic effect on the processing window of the $\mathrm{P} 3 \mathrm{HB}$ extrusion process was also observed after addition of the linear polyurethane. Moreover, the nanobiocomposites have higher thermal stability and wider range of processing temperatures compared to the unfilled matrix. The plasticizing influence of fillers was also determined based on the glass transition observation. The glass transition temperature decreases as the amount of fillers in the polymer matrix increases.

Summarizing, the beneficial effect of introducing two fillers, i.e., the organic clay and the polyurethane into the P3HB matrix was observed. Thermal and mechanical properties have improved. First of all, the processing capabilities of $\mathrm{P} 3 \mathrm{HB}$ have improved, making it a more useful polymer.

\section{Conclusions}

- New hybrid nanocomposites were prepared with the use of $\mathrm{P} 3 \mathrm{HB}$ as a matrix, Closite $30 \mathrm{~B}$ as a nanofiller in an amount of $1 \mathrm{wt} . \%$ and linear polyurethanes as a second filler. Second filler - linear polyurethanes (PU-MDI) based on diol with imidazoquinazoline rings and 4,4'-diisocyanate diphenylmethane was used in the mass content of 1 and $5 \%$.

- The producing process parameters of nanobiocomposites on the P3HB matrix are definitely more favorable than those ones of the unfilled P3HB and composites with the nanofiller. Nanobiocomposites show higher viscosity compared to the viscosity of the unfilled $\mathrm{P} 3 \mathrm{HB}$ at the same processing temperature.

- The thermal stability of hybrid nanobiocomposites based on the P3HB matrix during processing is higher and a temperature range for processing nano- biocomposites, compared to the unfilled $\mathrm{P} 3 \mathrm{HB}$ and nanocomposites without the addition of linear polyurethanes, is wider.

- The biggest difference between the temperature of degradation and the onset melting temperature was observed in the case of the nanocomposite containing $1 \%$ Cloisite $30 \mathrm{~B}$ and $5 \%$ of the linear polyurethane. The difference is about $100{ }^{\circ} \mathrm{C}$ and it is the significant advantage of the P3HB-1.5. It makes the material protected in the processing conditions.

- The presented thermal analysis showed a decrease of the following values: the glass transition temperature, melting temperature and the crystallization temperature with an increasing contain of nanofillers in the composites. A decrease of $T_{g}$ is linking with the plasticizing influence of fillers of nanobiocomposites.

- Based on the analysis of thermal history, the change of heat capacity for fully amorphous material and the heat of fusion for fully crystalline samples were estimated and were used to estimate the degree of crystallinity and degree of amorphous phase. The decrease of the degree of crystallinity content was noticed only for P3HB-1.5.

- The resulting hybrid nanobiocomposites have slightly better mechanical properties, substantially improved thermal characteristics, i.e., higher thermal stability and heat resistance, and a wider range of processing temperatures compared to the polymer matrix itself.

- Considering the biodegradability and biocompatibility of the polymer matrix, and the biocompatibility of polyurethanes, the resulting hybrid nanobiocomposites give new opportunities involving the manufacture of products from poly(3-hydroxybutyrate).

\section{References}

[1] Bakar M., Hausnerova B., Kostrzewa M., Effect of diisocyanates on the properties and morphology of epoxy/ polyurethane interpenetrating polymer networks, J. Thermoplast. Compos. Mater., 2012, 26 (10), 1364-1376, DOI: org/10.1177/ 0892705712439570.

[2] Bakar M., Kostrzewa M., Pawelec Z., Preparation and properties of epoxy resin modified with polyurethane based on hexamethylene diisocyanate and different polyols, J. Thermoplast. Compos. Mater., 2014, 27 (5), 620-631, DOI: org/10.1177/ 0892705712453155.

[3] Bakar M., Kostrzewa M., Hausnerova B., Sar K., Preparation and property evaluation of nanocomposites based on polyurethane-modified epoxy/montmorillonite systems, Adv. Polym. Tech., 2010, 29 (4), 237-248, DOI: 10.1002/adv.20192. 
[4] Baouz T., Rezgui F., Yilmazer U., Ethylene-methyl acrylate-glycidyl methacrylate toughened poly(lactic acid) nanocomposites, J. Appl. Polym. Sci., 2013, 128 (5), 3193-3204, DOI: 10.1002/app.38529.

[5] Chen G.Q., Wu Q., The application of polyhydroxyalkanoates as tissue engineering materials, Biomaterials, 2005, 26(33), 6565-6578, 10.1016/j.biomaterials.2005.04.036

[6] Czerniecka A., Magoń A., Schliesser J., Woodfield B.F., PYDA M., Heat capacity of poly(3-hydroxybutyrate), J. Chem. Thermodyn., 2014, 73, 76-84, DOI: org/10.2016/ j.jct.2013.10.020.

[7] CZERNIECKA-KUBICKA A., FrąCZ W., JASIORSKI M., BŁażejewski W., Pilch-Pitera B., Pyda M., ZarzyKa I., Thermal properties of poly(3-hydroxybutyrate) modified by nanoclay, J. Therm. Anal. Calorim., 2017, 125, 1513-1526, DOI: org/10.1007/s10973-016-6039-9.

[8] Czerniecka-Kubicka A., Schliesser J., Woodfield B.F., ZARZYKa I., Pyda M., Vibrational Heat Capacity of Poly(N-isopropylacrylamide), Polymer, 2015, 63, 108-115, DOI: org/10.1016/j.polymer.2015.02.051.

[9] Czerniecka-Kubicka A., ZarzyKa I., Pyda M., Advanced thermal analysis of poly(3-hydroxybutyrate), Przem. Chem., $2015,11,45-49$.

[10] CZerniecka-Kubicka A., ZarzyKa I., Pyda M., Advanced analysis of poly(3-hydroxybutyrate) phases based on vibrational heat capacity, J. Therm. Anal. Calorim., 2017, 127, 905-914, DOI: org/10.1007/s1097

[11] Doi Y., Kamesawa Y., Kunioka M., Saito T., Biodegradation of microbial copolyesters: poly(3-hydroxybutyrate-co-3-hydroxyvalerate) and poly(3-hydroxybutyrate-co-4-hydroxybutyrate), Macromolecules, 1990, 23 (1), 26-31.

[12] Fernandes E.G., Pietrini M., Chiellini E., Thermomechanical and morphological characterization of plasticized poly(R-3-hydroxybutyric acid), Macromolecular Symposia, 2004, 218, 157-164.

[13] GoŁęBIEwSKI J., GiBAS E., MALINOwSKI R., Wybrane polimery biodegradowalne - otrzymywanie, wtaściwości, zastosowanie, Polimery, 2008, 53, $799-807$ (in Polish).

[14] Hablot E., Bordes P., Pollet E., Averous L., Thermal and thermo-mechanical degradation of poly(3-hydroxybutyrate)based multiphase systems, Polym. Degrad. Stabil., 2008, 93 (2), 413-421, DOI: 10.1016/j.polymdegradstab.2007.11.018.

[15] JANigOvÁ I., LACíK I., CHODÁK I., Thermal degradation of plasticized poly(3-hyd-roxybutyrate) investigated by DSC, Polym. Degrad. Stabil., 2002, 77 (1), 35-41, DOI: 10.1063/1.4918384.
[16] Kostrzewa M., Hausnerova B., Bakar M., Dalka M., Property evaluation and structure analysis of polyurethane/ epoxy graft interpenetrating polymer networks, J. Appl. Polym. Sci., 2011, 122, 1722-1730, DOI: org/10.1002/ app.34070.

[17] Kostrzewa M., Hausnerova B., Bakar M., PająK K., Preparation and characterization of an epoxy resin modified by a combination of MDI-based polyurethane and montmorillonite, J. Appl. Polym. Sci., 2011, 122, 3237-3247, DOI: org/10.1002/app.34347.

[18] LeE S.N., LEE M.Y., PARK W.H., Thermal stabilization of poly(3-hydroxybutyrate) by poly(glycidyl methacrylate, J. Appl. Polym. Sci., 2002, 83 (13), 2945-2952, DOI: org/ 10.1002/app.10318.

[19] Magoń A., Pyda M., Study of crystalline and amorphous phases of biodegradable poly(lactic acid) by advanced thermal analysis, Polymer, 2009, 50, 3967-3973, DOI: 10.1016/ j.polymer.2009.06.052.

[20] PaK J., Qiu W., Pyda M., Nowak-Pyda E., Wunderlich B., Can One Measure Precise Heat Capacities with DSC or TMDSC? A Study of the Baseline and Heat-flow-rate Correction, J. Thermal. Anal. Calorimetry, 2005, 82, 565-574, DOI: $10.1007 / \mathrm{s} 10973-005-0935-8$.

[21] Panayotidou E., Baklavaridis A., Zuburtikudis I., ACHILlAS D.S., Nanocomposites of poly(3-hydroxybutyrate)/organomodified montmorillonite: Effect of the nanofiller on the polymer's Biodegradation, J. Appl. Polym. Sci., 2015, 132 (11), 41656-41663, DOI: org/10.1002/ app.41656.

[22] PyDA M., Temperature-Modulated Differential Scanning Calorimetry (TMDSC), [in:] Encyclopedia of Polymer Science and Technology, John Wiley \& Sons, Inc., 2014, 1-30, DOI: $10.1002 / 0471440264$.

[23] Pyda M., Czerniecka-Kubicka A., Thermal Properties and Thermodynamics of Poly(l-lactic acid), [in:] M.L. Di Lorenzo, R. Androsch (Eds.), Synthesis, Structure and Properties of Poly(lactic acid), Springer International Publishing, Cham 2018, 153-193, DOI: 10.1007/12_2017_19.

[24] SZyszKowska A., CZERNIECKA-KUBICKA A., PydA M., BYCZYŃSKi Ł., GANCARCZYK K., SEDLARIK V., ZARZYKA I., Linear polyurethanes with imidazoquinazoline rings - preparation and properties evaluation, Polym. Bull., 2019, DOI: 10.1007/s00289-019-02702-5.

[25] Wunderlich B., Thermal Analysis of Polymeric Materials, Springer, Berlin, Heidelberg, New York 2005. 